\title{
Neue Brenthiden aus Sumatra nebst Bemerkungen zu schon bekannten Arten.
}

\section{Von R. Kleine, Stettin.}

(Mit 1 Abbildung.)

Herr J. B. Corporaal-Medan, dem ich schon mehrere Sendungen Brenthiden von der Ostküste Sumatras zu verdanken habe, schickte mir wieder eine kleine Kollektion von 44 Stück, die mehrere neue Arten enthielt. Aulserdem ist sie durch sorgfältige Fundortangabe, auch in bezug auf Zeit und Höhenlage ausgezeichnet.

\section{Calodromini.}

1. Calodromus Mellyi Guér. Diese interessante Art sah ich von Vorderindien über Malakka und den Sunda-Inseln bis zu den Philippinen. An der Ostküste Sumatras muls sie direkt häufig sein, sie findet sich in fast jeder Sendung aus jener Gegend. Bandar Baroe, 10.2. 21 in $850 \mathrm{~m}$ Seehöhe.

2. Opisthenoxys ochraceus Kleine. Ich habe diese Art von den Philippinen beschrieben und bisher nur von dort gesehen. Mir liegt ein typisches Stück von Bandar Baroe, 11. 2. 21 in $850 \mathrm{~m}$ Seehöhe gefunden, vor. Die Verbreitung ist also eine sehr weite und die Art ist nicht für die Philippinen typisch. Da die Philippinen z. T. von Westēn her besiedelt sind und 0 . ochraceus durchaus westlichen Typus besitzt, kann es keinem Zweifel unterliegen, dafs wir einen nach Osten vorgedrungenen Wanderer vor uns haben. Möglicherweise findet sich die Art auch noch auf Borneo und Palawan.

\section{Stereodermini.}

3. Jonthocerus angulaticeps Senna. Bandar Baroe, 9. 2. 21, $850 \mathrm{~m}$ Seehöhe. Auf der Ostküste Sumatras scheinbar nicht selten. Auch auf Borneo bis zur Ostküste gefunden, wohl nicht gerade selten und weit verbreitet.

4. Jonthocerus asiaticus Kleine. Brastagi, $1300 \mathrm{~m}$ Seehöhe. Kein anderer Jonthocerus wurde in solchen Höhenlagen gefunden.

5. Jonthocerus angustifrons n. sp. Kastanienbraun, Elytren schwarz, höchstens der Humerus etwas rotbraun aufgehellt, Schenkel an Basis und Knie etwas angedunkelt, Elytren matt, sonst glänzend. Kopf durchgehend gefurcht, Hinterecken stumpf, obsolet, Stirn sehr schmal, Augen grofs, Metarostrum kräftig gefurcht, Prorostrum eben. Fühler weils behaart. Prothorax kräftig, durchgehend gefurcht, 2. Rippe auf den Elytren hinter der Mitte verloschen. 
Länge (total): 4,5-5,0 mm. Breite (Thorax): $0,8 \mathrm{~mm}$ zirka.

Fundort: Ostküste von Sumatra, Marihat, 2. 4. 1918, und Pagar Marbau, 1. 4. 18 in $24 \mathrm{~m}$ Seehöhe. Von J. B. Corporaal gesammelt. Typen in seinem und meinem Besitz.

Es handelt sich um eine zierliche Art, die mit crematus Lacordaire und sondaicus Senna verwandt ist. Von erster Art unterscheidet sie sich durch die Ausfärbung leicht. Bei allen crematus-Stücken, die ich sah, war die Ausfärbung konstant, und zwar genau, wie sie Lacord. angibt. Alle typischen Stücke dieser Art stammten von Ceylon, ich bezweifle das Vorkommen in Sumatra, wahrscheinlich liegt Verwechslung mit einer anderen Art vor. Von sondaicus, dem angustifrons am ähnlichsten ist, trennen sofort die schmale Stirn und die grofsen Augen.

6. Cerobates sexsulcatus Motsch. Pagar Marbau, 4. 4. 20, $24 \mathrm{~m}$ Seehöhe. Gemein von Ceylon bis Neu-Guinea.

7. C. sumatranus Senna, von Bandar Baroe, 9. 2. $21,850 \mathrm{~m}$ Seehöhe.

\section{Trachelizini.}

8. Trachelizus laevigatus Senna. Der Autor beschrieb die Art von Java. Sie ist aber sehr weit verbreitet und kommt auf den grofsen Sundainseln überall vor. Übrigens scheint es sich auch um eine häufige Art zu handeln. Brastagi, in $1300 \mathrm{~m}$ Seehöhe, 14. 2. 21.

9. Hypomiolispa sponsa. Kleine. Von Sumatra über Borneo bis zu den Philippinen, auf Java noch nicht gefunden. Bandar Baroe, 12. 2. 21, $850 \mathrm{~m}$ Seehöhe.

10. H. F a usti Senna. Dieselbe Verbreitung. Balimbingan, 8. 20, $370 \mathrm{~m}$ Seehöhe.

11. \& H. opposita n. sp. Schwarz, Prorostrum, Fühler, Schenkel und Schienen in einem breiten Mittelbande, das Klauenglied und die Elytren an den weiter unten angegebenen Stellen hellrotbraun, am ganzen Körper glänzend.

Kopf hinten wenig eingebuchtet, mit tiefer Mittelfurche und allgemein grober Punktierung, die seitlich über den Augen liegende Furche tief, keilförmig. Der hinter den Augen liegende Kopfteil glatt, stumpf-zweispitzig, etwa so breit wie der Augendurchmesser. Unterseite mit dreieckiger Gularfurche, jederseits daneben eine dreieckige, kurze, aber breite Einbuchtung, Skulptur fehlt. Augen ohne Besonderes.

Metarostrum dreifurchig, Mesorostrum gegen die Mitte gewölbt, Furche schmal, Prorostrum \pm 4 kantig, an der Basis mit Rudimenten einer flachen, breiten Furche, Skulptur nadelstichig. 
Fühler gedrungen, keulig, 2.-8. Glied scharfkantig, nur die Hinterkante etwas rundlich, bedeutend breiter als lang, locker stehend, 9. und 10. Glied vergröfsert, 9. etwa quadratisch, 10 . bestimmt breiter als lang, Endglied kurz, kegelig, vom 3. ab kräftig behaart.

Prothorax gegen den Hals verengt, gefurcht, tief, rugos punktiert, seitliche Halspartie und Prosternum unskulptiert.

Elytren in der üblichen Weise skulptiert, die Ausfärbung ist folgende: Im Bereich der 5. und 6. Rippe ein roter Basalstreifen von etwa $1 / 5$ Deckenlänge, desgl. eine postmediane Makel in üblichem Umfang und an üblicher Stelle und der Deckenabsturz.

Beine ohne Besonderes, das Klauenglied aber auffällig dick, robust walzig, nicht wie sonst keulig. Metasternum und Abdomen rugos skulptiert.

Länge (total): $11 \mathrm{~mm}$. Breite (Thorax): $2 \mathrm{~mm}$.

Fundort: Bandar Baroe, 9. 2. 21, $850 \mathrm{~m}$ Seehöhe.

Die neue Art, die mir leider nur in einem weiblichen Stück vorlag, steht allen bisher bekanntgewordenen Hypomiolispa-Arten durch die Art und

Decken-

zeichnungvon

Hypomiolispa opposita n. sp.

Die roten

Partien sind hell geblieben. Weise der Ausfärbung entgegen. Diejenigen Elemente, die sonst schwarz sind, vor allen Dingen die postmediane Makel und der Absturz, sind in demselben Umfang, rot, in welchem man sonst die schwarzen Farben findet. Diese vollständige Umkehrung der Ausfärbung ist mir noch nicht vorgekommen. Ebenso ungewöhnlich ist die Farbe der Beine, bisher sind noch keine zweifarbigen beobachtet. Endlich ist noch darauf hinzuweisen, dafs die Klauenglieder walzig sind.

Opposita gehört in Abt. 2 meiner Bestimmungstabelle ${ }^{1}$ ) und nimmt daselbst eine besondere Stellung, die noch festzulegen ist, ein.

Typus in meinem Besitz.

12. Hy ро miolispa Pasteuri Senna. Bandar Baroe, 10.2. 21, $850 \mathrm{~m}$ Seehöhe. Von der Ostküste Sumatras sah ich schon mehrfach Stücke aus Saekaranda, Hauptverbreitung scheint aber in Java zu liegen. Aus anderen Teilen Sumatras sah ich die Art noch nicht.

13. Hoplopisthius trichimerus Senna. Medan, 11. 1. 21, $20 \mathrm{~m}$ Seehöhe. Sehr weit verbreitete Art.

1) cfr. Die Gattung Hypomiolispa Kleine, Ent. Bl. 14, 1918, p. $76 \mathrm{ff}$. 


\section{Arrhenodini.}

14. B aryrrhynchus dehiscens Gyll. Bandar Barve, 10. 2. 21, $850 \mathrm{~m}$ Seehöhe. Boschres Bandar, 4. 19, $90 \mathrm{~m}$ Seehöhe. Sunda-Inseln allgemein.

15. Prophthalmus pugnator Pow. Tjinta Radja, $7 \mathrm{~m}$ Seehöhe. Dürfte gleichfalls wenigstens auf Java und Sumatra ziemlich verbreitet sein, von der Ostküste ist das der erste mir bekanntgewordene Fundort.

16. Corporaalia baryrrhynchoides Kleine. Von dieser äufserst interessanten Gattung sah ich ein ơ? 26. 12. 17, $24 \mathrm{~m}$ Seehöhe, Tandjong Merah, 6. 19, $22 \mathrm{~m}$ Seehöhe. Alle bisher bekannten Stücke stammen von der Ostküste Sumatras.

17. Eupeithes barbarus Kleine. Siantar, 8. 20, $400 \mathrm{~m}$ Seehöhe. In bezug auf Verbreitung gilt dasselbe wie bei 16 .

18. Caenorychodes serrirostris F. Medan, 16. 4. 21, $20 \mathrm{~m}$ Seehöhe, Pagar, Marbau, 4. 4. 20, $24 \mathrm{~m}$ Seehöhe, Boschres Bandar, 30. 9. 19, $90 \mathrm{~m}$ Seehöhe. Gemein auf den Sundainseln.

\section{Ceocephalini.}

19. Hormocerus reticulatus F. Überall an der Ostküste gemein.

20. Apterorrhinus compressitarsus Senna. Boschres Bandar, 17. 1. 20, $90 \mathrm{~m}$ Seehöhe. Die Art kommt auch auf den Philippinen vor, ist von S.-Sumatra bekannt, dürfte wohl auf der ganzen Linie: Sumatra-Borneo-PalawanPhilippinen $\mathrm{zu}$ finden sein. Vielleicht sogar im ganzen Verbreitungsgebiet des Hormocerus, mit dem sie äufserst nahe verwandt ist.

\section{Ithystenini.}

21. Cediocera tristis Senna. Bandar Baroe, 10. 2. 21 , $850 \mathrm{~m}$ Seehöhe. Weitverbreitete Art. 


\section{$2 \mathrm{BHL}$ Biodiversity Heritage Library}

1922. "Neue Brenthiden aus Sumatra nebst Bemerkungen. zu schon bekannten Arten." Deutsche entomologische Zeitschrift 1922, 148-151. https://doi.org/10.1002/mmnd.192219220113.

View This Item Online: https://www.biodiversitylibrary.org/item/103380

DOI: https://doi.org/10.1002/mmnd.192219220113

Permalink: https://www.biodiversitylibrary.org/partpdf/41398

\section{Holding Institution}

Harvard University, Museum of Comparative Zoology, Ernst Mayr Library

\section{Sponsored by}

Biodiversity Heritage Library

\section{Copyright \& Reuse}

Copyright Status: Public domain. The BHL considers that this work is no longer under copyright protection.

This document was created from content at the Biodiversity Heritage Library, the world's largest open access digital library for biodiversity literature and archives. Visit BHL at https://www.biodiversitylibrary.org. 